\title{
EXCITATION PROCESSES IN COMETARY COMAE
}

\author{
P.D.Singh \\ Department of Astronomy, Institute of Astronomy \& Geophysics, \\ University of São Paulo, Av. Miguel Stefano 4.200,C.P.30.627, \\ São Paulo, Cep. 04301 , São Paulo, Brasil.
}

ABSTRACT:- Excitations of cometary $\mathrm{NH}$ and $\mathrm{S}_{2}$ molecules are discussed. Photodissociation and dissociative electron recombination processes may be sources of meta-stable nitrogen $\left({ }^{2} P^{0},{ }^{2} D^{0}\right)$ atoms in comets.

I.Introduction:- The nucleus of a comet is beleived to contain frozen votatile chemical compounds which are evaporated and are then decomposed by solar radiation field when a comet approaches (or recedes) the sun (Whipple, 1950). The decomposed material surrounds the nucleus and develops an expanding atmosphere of gas and dust which is referred as the coma of a comet and contains dust (possibly ice-coated grains), molecules, neutral radicals, atomic species and molecular ions that are released from the nucleus with velocities of about $0.5-1 \mathrm{~km} \mathrm{~s}^{-1}$. Over the past centuary a considerable amount of information has been obtained about the composition of coma through spectral line studies extending from ultraviolet (uv) to radiowave (rw) region (see Wyckoff, 1982).

II.Excitation of NH:- The NH radical is known to exist in cometary comae (Swings and Haser, 1956), through identification of $(0,0)$ transition of $\mathrm{NH}\left(A^{3} \pi-X^{3} \Sigma\right)$ at $3360 \AA$. Recent calculation by Litvak and Kuiper(1982) shows that the resonance fluorescence mechanism is operative for $3360 \AA$ band of the $\mathrm{NH}$ radical in comets.Lifetime measurements of $\mathrm{NH}$ by high frequency deflection technique (Smith et al. 1976) show that $v^{\prime}=2$ level of NH $A^{3} \pi$ state undergoes in a predissociation process via spin-orbit coupling $\left(A^{3} \pi, 5 \Sigma\right)$ similar to that of $\mathrm{OH}$. At sun-comet distance $=1$ $\mathrm{AU}$, the lifetime of cometary $\mathrm{NH}$ radical varies from $1.310^{4} \mathrm{~s}$ to $2.310^{4} \mathrm{~s}$ for a comet of radial velocity ranging from $-80 \mathrm{~km} \mathrm{~s}^{-1}$ to $+80 \mathrm{~km} \mathrm{~s}^{-1}$. Photodissociation of $\mathrm{NH}$ by absorption of solar photons through $\mathrm{V}^{\prime}=2$ level of $\mathrm{NH} A^{3} \pi$ state leads $\mathrm{NI}\left({ }^{4} \mathrm{~S}^{\circ}\right)$ and $\mathrm{HI}\left({ }^{2} \mathrm{~S}\right)$ atoms with corresponding velocity of $1 \mathrm{~km} \mathrm{~s}^{-1}$ and $15 \mathrm{~km} \mathrm{~s}^{-1}$. Photodissociation of cometary $\mathrm{NH}_{3}$ (Altenhoff et al 1983) may result NH radical in a process as described by Jackson (1976). At $r=1$ AU, total photodissociation lifetime of amonia is about $5.6510^{3} \mathrm{~s}$ (Huebner and Carpenter, 1979). If an outstream velocity of $\mathrm{NH}$ parent is assumed to be of the order of $1 \mathrm{~km} \mathrm{~s}^{-1}$ then Combi's diaphragm convolution model NH parent scale length, scaled at $r=1 \mathrm{AU}$, would be of about $5.410^{3} \mathrm{~km}$ (Combi, 1978). 
III.Excitation of NI:-Dissociative electron recombination process of $\mathrm{N}_{2}^{+}$ with electron may be a source of NI $\left({ }^{2} \mathrm{P}^{\circ},{ }^{2} \mathrm{D}^{0}\right)$, atoms in cometary comae (Queffelec et al. 1985). In addition, photodissociation of CN by absorption of solar photons may also result meta-stable nitrogen atoms (Lavendy et al. 1984). The radiative lifetimes of $\mathrm{NI}\left({ }^{2} p^{\circ}\right)$ and $\mathrm{NI}\left({ }^{2} D^{\circ}\right)$ states are about $5.39 \mathrm{~s}$ and $3.6410^{4} \mathrm{~s}$, respectively (zeippen, 1982). At $r=1 \mathrm{AU}$, the photoionization rates by solar uitraviolet photons for $N I\left({ }^{4} S^{\circ}\right)$, NI $\left({ }^{2} D^{\circ}\right)$ and $\mathrm{NI}\left({ }^{2} \mathrm{P}^{\circ}\right)$ states are $1.8510^{-7}, 1.6510^{-7}$ and $1.9610^{-7} \mathrm{~s}^{-1}$, respectively. The g-factors, at $r=1 \mathrm{AU}$, for NI $\left({ }^{4} P-{ }^{4} S^{0}\right), N I\left({ }^{2} P-{ }^{2} D^{\circ}\right)$ and $N I\left({ }^{2} P-{ }^{2} P^{\circ}\right)$ transitions, which occur at 1200, 1493 and $1743 \mathrm{~A}$, are $1.110^{-5}, 1.910^{-6}$ and $6.910^{-6} \mathrm{~s}^{-1}$, respectively. The $1200 \AA$ line would be masked by strong Lyman alpha emission of $H$-atom. If $g=g_{e} r^{-2}\left(g_{e}\right.$ is the g-factor at $r=1$ AU) the line NI $\left({ }^{2} P-{ }^{2} D^{0}\right)$ at $1493 \AA$ would be excitable by resonancefluorescence mechanism and may be seen in comets when $r$ is less than $0.25 \mathrm{AU}$. The weak line at $5201.1 \AA$ observed in the spectra of several comets (Swings and Haser, 1956) could be due to forbidden NI $\left({ }^{2} D^{\circ}-{ }^{4} S^{\circ}\right)$ transition (Cosmovici and Ortolani, 1980). The theoretical estimate of intensity ratio NI $\left({ }^{2} P^{0}-{ }^{2} D^{\circ}\right) / N I\left({ }^{2} D^{\circ}-{ }^{4} S^{\circ}\right)$ is of the order of unity and does not depend on solar cycle. The line 5201.1 $\AA$ is too weak for any quantitative analysis.

IV. Excitation of $S_{2}$ :-Emission bands due to $S_{2}\left(B^{3} \Sigma_{u}^{-}-x^{3} \Sigma_{g}\right)$ transition in the range 2829-3058 $8^{2}$ have been observed in the uv spectra of comet IRAS Araki-Alcock (1983d) (A'Hearn et al.1983). The observed intensities are in agreement with the intensities estimated by resonance scattering. An abundance of $310^{27} \mathrm{~S}_{2}$ molecules was derived for comet (1983d) by A'Hearn et a1. (1983). Vibrational levels $v^{\prime} \geqslant 10$ of the $B^{3} \Sigma_{u}$ state predissociate and predissociation efficiency of $v^{\prime}=10$ level is 0.92 (Ricks and Barrow, 1969). At $r=1 \mathrm{AU}$, absorption of solar uv photons of wavelength $\sim 280 \mathrm{~nm}$ leads to a dissociation lifetime of about $250 \mathrm{~s}$ for $\mathrm{S}_{2}$ (de Almeida and Singh, 1986) which is a factor of two lower than that used by A'Hearn et al. (1983). Since solar flux at wavelength $\sim 280 \mathrm{~nm}$ does not vary much we have neglected the dependence of lifetime of $S_{2}$ on heliocentric velocity of comet. $\mathrm{A} \mathrm{S}_{2}$ production rate of about $1.210^{25} \mathrm{~s}^{-1}$ is derived for comet (1983d) which is comparable to CS production rates derived for comet (1983d) (A'Hearn et al. 1983), Bradfield (Jackson et al. 1982) and Encke (Feldman et a1. 1984; Weaver et a1. 1981) when the data are compared at about the same heliocentric distance. If $Q\left(\mathrm{H}_{2} \mathrm{O}\right) \sim 10^{29} \mathrm{~s}^{-1}$ for comet $(1983 d)$, the ratio $Q\left(\mathrm{~S}_{2}\right) / Q\left(\mathrm{H}_{2} \mathrm{O}\right) \sim 10^{-4}$. Observed spatial profile of the $(7,0)$ band indicates that ${ }^{2} S_{2}$ are released very near to the nucleus of the comet (1983d) (A'Hearn et al. 1983). For comet Bradfield, the CS and $S$ production rates follow about the same heliocentric variation $(Q(C S) \propto$ $r^{-5}$ and $Q(S) \propto r^{-5.4}$ ) and thus indicate a common parent for both species (Jackson et al. 1982). Photodissociation of $\mathrm{CS}_{2}$ at wavelength of the order of $193 \mathrm{~nm}$ (Yang et a1. 1980) yields:

$$
\begin{aligned}
& \mathrm{CS}_{2}+h \nu \rightarrow C S\left(X^{2} \Sigma^{+}\right)+S\left({ }^{3} P\right) \\
& C S_{2}+h \nu \rightarrow C S\left(X^{1} \Sigma^{+}\right)+S\left({ }^{1} D\right)
\end{aligned}
$$


CS vibrationally excited to $v^{\prime \prime}=7$ and branching ratio is $20 \%$ for (1) and $80 \%$ for (2). The radiative 1 ifetime of $S\left({ }^{2} D\right)$ state is about $28 \mathrm{~S}$ (Weise et al 1966) and, analogous to OI, transitions: $\mathrm{SI}^{1}\left(\mathrm{D}_{2}-{ }^{3} \mathrm{P}_{1}\right)$ and SI $\left({ }^{1} D_{2}-{ }^{3} P_{2}\right)$ may be detectable at $11305.8 \AA$ and $10819.8 \AA$, respectively, in comets. In the inner coma, the reaction:

$$
\mathrm{S}\left({ }^{1} \mathrm{D}\right)+\mathrm{CS}_{2} \rightarrow \mathrm{CS}+\mathrm{S}_{2}
$$

may result $S_{2}$ in $v^{\prime \prime} \leqslant 8$ of the $x^{3} \Sigma_{g}$ state (Venkitchalam and Krishnamachari, 1980). The excited $S_{2}$ molecules will come to the $v^{\prime \prime}=0$ level by collision deactivation process. The rate constant of (3) is not known. $\mathrm{H}_{2} \mathrm{~S}$ is isovalent to $\mathrm{H}_{2} \mathrm{O}$ and photodissociation of hydrogen sulphide wilt result $\mathrm{SH}$ which by neutral-radical reaction may yield $\mathrm{S}_{2}$ :

$$
\begin{aligned}
& \mathrm{H}_{2} \mathrm{~S}+\mathrm{h \nu}(193 \mathrm{~nm}) \rightarrow \mathrm{SH}+\mathrm{H} \\
& \mathrm{SH}+\mathrm{S} \longrightarrow \mathrm{S}_{2}+\mathrm{H}
\end{aligned}
$$

The dissociation energy of $\mathrm{H}_{2} \mathrm{~S}$ is about $3.26 \mathrm{eV}$ compared to dissociation energy of water molecule of about $5.1136 \mathrm{eV}$ and photodissociation of $\mathrm{H}_{2} \mathrm{~S}$ yields a velocity distribution of about $16 \mathrm{~km} \mathrm{~s}^{-1}$ for hydrogen atoms which fits well with high component $H$-atoms found in comets (Festou et a1. 1983). The $(0,0)$ band of $\operatorname{SH}\left(A^{2} \Sigma-X^{2} \pi\right)$ appears at $3261 \AA$ and would be blended with cometary $\mathrm{CO}_{2}^{+}$emission (Festou et al. 1982). Further, $\mathrm{H}_{2} \mathrm{~S}^{+}$ (ionization potential of $\mathrm{H}_{2} \mathrm{~S}$ is $\sim 10.472 \mathrm{eV}$ compared to ionization potential of $\mathrm{H}_{2} \mathrm{O}=12.618 \mathrm{eV}$ ) ion has recently been identified in comet(1983d) by Cosmovici and Ortolani (1984) and Bradfield by Cosmovici et al. (1982). $\mathrm{H}_{2} \mathrm{~S}$ is known to occur in interstellar sources (Thaddeus and Kutner, 1972) and cometary theoretical models (Yamamoto et al. 1983) having interstellar compositions have resulted cometary molecular abundances in agreement with those found in comets. This suggests an indirect evidence of $\mathrm{H}_{2} \mathrm{~S}$ in the nucleus of a comet. A recent attempt for detection of $\mathrm{H}_{2} \mathrm{~S}$ at ${ }^{2} 1.59$ micron band in comet West by Johnson et al. (1983) was unsuccessful. If $k_{5}$ $10^{-11} \mathrm{~cm}^{3} \mathrm{~s}^{-1}$ (typical neutral-radical reaction rate constant - Liszt, ${ }_{1978 \text {, }}$ Millar, 1982) the time scale for reaction (5) would be about 28 hours when the density in the inner coma is of the order of $10^{6} \mathrm{~cm}^{-3}$.

V.Acknowledgement:- I am thankful to FAPESP, São Paulo for a travel grant under contract no 85/2105-2.

\section{$\underline{\text { References }}$}

Altenhoff,W. J., Batrla,W.,Huchtmeier,W.K., Schmidt, J., Stumpff,P. and Walms ley, M.: 1983, Astron. Astrophys. 125, L19.

A'Hearn,M.F., Feldman,P.D. and Schleicher,D.G.:1983,Ap.J. ,274, L99. Combi ,M.R.: 1978, Astron. J. , 83, 1459.

Cosmovi ci, C. B. ,Barbieri, C.,Bonol i ,C.,Bortoletto,F. and Hamzaoglu,E.:1982, Astron. Astrophys., 114, 373.

Cosmovici,C.B. and Ortolani,S.: T984, Nature, 310, 122. 
Cosmovici,C.B. and Ortolani,S.: 1980, Astron. Astrophys., 88, L16. de Almeida,A.A. and Singh,P.D.: 1986, Moon \& Plan, (in pre $\overline{s S}$ ).

Feldman,P.D., Weaver,H.A. and Fes tou,M.C.: 1984, I carus, 60, 455.

Festou,M.C., Feldman,P.D. and Weaver,H.A.: 1982 , Ap.J., 256, 122.

Festou,M.C. ,Keller,H.U., Bertaux, J.L. and Barker,E.S. :1983, Ap.J. ,265, 925. Huebner,W.F. and Carpenter,C.W.: 1979,Los Alamos Sci. Lab.,LA-8085-MS, Los Alamos, New Mexico 87545.

Johnson,J.R. ,Fink,U. and Larson,H.P.: 1983, Ap.J., 270, 769.

Jackson,W.M., Halpern, J.B.,Feldman,P.D. and Rahe, J.:T982, Astron. Astrophysics., 107, 385 .

Jackson.W.M.: 1976, J.Photochem., 5, 107.

Liszt,H.S.: 1978, Ap.J., 219, 454.

Litvak,M.M. and Kuiper,E.N.R.: 1982, Ap.J., 253, 622.

Lavendy, H., Gandara,G. and Robbe, J.M.: 1984, J.Mo1. Spectros C. ,106, 395.

Millar,T.J.: 1982 , MNRAS, 199, 309.

Queffelec,J.L., Rowe, B.R., Morl ais, M., Gomet, J.C. and Vallee,F.: 1985 , P1an.Sp.Sci., 33, 263.

Ricks, J.M. and Barrow,R.F.: 1969, Can.J.Phys., 47, 2423.

Smith,W.H., Brzozowski,J. and Erman,P.: 1976, J.Chem.Phys., 64, 4628.

Swings, $P=$ and Haser, $L_{\text {.: }}$ 1956, 'At las of Representative Cometary Spectra'. Thaddeus,P. and Kutner,M.L.: 1972, Ap.J.Lett., 176, L75.

Venkitachal am,T.V. and Krishnamachari,S.L.N.G.: T980, Ind. J.Phys., 54B,282. Weise,W.L., Smith,M.W. and Glenon,B.M.: 1966, 'Atomic Transition Probabilities', NSRDS-NBS-4.

Weaver,H.A.,Feldman,P.D. ,Festou,M.C. and A'Hearn,M.F.: 1981 , I carus, $47,449$. Whipple,F.L.: 1950,Ap.J., $111,375$.

Wyckoff,S.: 1982, in 'Comets', L.L.Wilkening (ed.), University of Arizona Press, Tucson, Az.

Yamamoto,T. ,Nakagawa,N. and Fukui,Y.: 1983, Astron. Astrophys., 122,171. Yang,S.C., Freedman, A. , Kawasaki, M. and Bersolm, R.:1980, J.Chem. Phys. ,72, 4058.

Zeippen,C.J.: 1982, MNRAS, 198, 111.

\section{DISCUSSION}

MITCHELL: It is premature to rule out interstellar $s_{2}$ as the source of cometary $s_{2}$. The observed interstellar upper limit is not restructure, being $s_{2} / n \leqq 10^{-6}$ (Liszt 1978). An ion-molecule route to $s_{2}$ is $\mathrm{S}^{+}+\mathrm{H}_{2} \mathrm{~S} \rightarrow \mathrm{S}_{2} \mathrm{H}^{+}+\mathrm{H}, \quad \mathrm{S}_{2} \mathrm{H}^{+}+\mathrm{e} \rightarrow \mathrm{S}_{2}+\mathrm{H}, \quad \mathrm{S}_{2}$ is destroyed by $\mathrm{C}$ and $\mathrm{O}$. If interstellar $C$ and $O$ are low in abundance or if the activation energy is reaonably high, $S_{2}$ abundance should result. The above path to $s_{2}$ has yet to be included in kinetic calculations. 
P.D. FELDMAN: I like to comment on your scheme as I find it completely in disagreement with the data that I showed the other day. You produce ${ }^{1_{D}}$ sulphur from dissociation of $\mathrm{CS}_{2}$ and $\mathrm{SH}$ from dissociation of $\mathrm{H}_{2} \mathrm{~S}$. Both of these need certain time while molecules are going to flow out and then you require two-body collision, which is relatively unlikely. Therefore, I find that any $\mathrm{H}_{2} \mathrm{~S}$ you produce cannot be concentrated so close to the nucleus as we observed. P.D. SINGH: I agree with you. 